\title{
Educação Patrimonial Nos Anos Finais Do Ensino Fundamental: Uma Analise Das Metodologias Aplicadas Em Sala
}

\author{
Educación Patrimonial En Los Años Finales De La Enseñanza \\ Fundamental: Una Analisis De Las Metodologías Aplicadas En Sala \\ Patrimonial Education In The Final Years Of Fundamental Teaching: \\ Annalysis Of The Methodologies Applied In The Room
}

Danilo Pedro Jovino ${ }^{1}$

Hermogenes De Sousa Cerqueira Filho

\begin{abstract}
Resumo
O presente trabalho é desenvolvido pela Universidade Federal do Pampa - UNIPAMPA, campus São Borja - RS, especificamente no curso de Licenciatura em Ciências Humanas, em financiamento com o CNPq e CAPES, desenvolvem o Programa Institucional de Bolsa de Iniciação à Docência - PIBID, uma política pública educacional em parceria com a universidade e o Colégio Estadual Getúlio Vargas. O objetivo deste trabalho é verificar se as metodologias e estratégias pedagógicas utilizadas em sala, estão orientando os alunos de maneira que os levem a conhecer sua herança cultural, tendo como fonte primaria de conhecimento o patrimônio cultural de São Borja. O grupo de pibidianos do subprojeto história, no decorrer do ano de 2017, desenvolveram um projeto de educação patrimonial com alunos do $8^{\circ}$ ano do ensino fundamental. No decorrer das aulas surgiu a necessidade de verificar se os alunos estavam conseguindo relacionar o conteúdo ministrado nas aulas, com o patrimônio existente na cidade, através de um questionário aberto. Assim pautados pela a metodologia qualiquanti e os métodos historiográfico, hermenêutico e analítico desenvolvemos a presente pesquisa. Os resultados obtidos com esta pesquisa indicaram que os alunos conseguiram assimilar a teoria e relaciona-la com a pratica, ou seja, compreender o que é patrimônio cultural e conhecer os patrimônios que fazem parte da sua história. Além de indicar uma satisfação com programa, as metodologias utilizadas em sala e o tema escolhido para o ano letivo.
\end{abstract}

Palavras-Chave: PIBID; Educação Patrimonial; Metodologias.

\section{Resumen}

El presente trabajo es desarrollado por la Universidad Federal de Pampa - UNIPAMPA, campus São Borja - RS, específicamente en el curso de Licenciatura en Ciencias Humanas, en financiamiento con el CNPq y CAPES, desarrollan el Programa Institucional de Beca de Iniciación a la Docencia - PIBID, una política pública educativa en asociación con la universidad y el Colegio Estadual Getúlio Vargas. El objetivo de este trabajo es verificar si las metodologías y estrategias pedagógicas utilizadas en la sala, están orientando a los alumnos de manera que los lleven a conocer su herencia cultural, teniendo como fuente primaria de conocimiento el patrimonio cultural de San Borja. El grupo de pibidianos del subproyecto histórico, a lo largo del año 2017, desarrollaron un proyecto de educación patrimonial con alumnos del $8^{\circ}$ año de la enseñanza fundamental. En el curso de las clases surgió la necesidad de verificar si los alumnos estaban logrando relacionar el contenido ministrado en las

\footnotetext{
${ }^{1}$ Mestrando do programa de Pós Graduação em Políticas Públicas da Universidade Federal do Pampa UNIPAMPA; bacharel em Ciências Sociais - Ciência Política e graduando em Licenciatura em Ciências Humanas pela mesma instituição; São Borja, Rio Grande do Sul, Brasil; danilopedro_gda@ hotmail.com

${ }^{2}$ Graduando em Licenciatura em Ciências Humanas pela Universidade Federal do Pampa - UNIPAMPA; São Borja, Rio Grande do Sul, Brasil; hermogenesfilho13@gmail.com
} 
clases, con el patrimonio existente en la ciudad, a través de un cuestionario abierto. Así pautados por la metodología cuali-quanti y los métodos historiográfico, hermenéutico y analítico desarrollamos la presente investigación. Los resultados obtenidos con esta investigación indicaron que los alumnos lograron asimilar la teoría y relacionarla con la práctica, o sea, comprender lo que es patrimonio cultural y conocer los patrimonios que forman parte de su historia. Además de indicar una satisfacción con programa, las metodologías utilizadas en sala y el tema elegido para el año escolar.

Palabras claves: PIBID; Educación Patrimonial; Metodologías.

\begin{abstract}
The present work is developed by the Federal University of Pampa - UNIPAMPA, Campus São Borja - RS, specifically in the degree course in Human Sciences, in financing with CNPq and CAPES, develop the Institutional Program of Initiation to Teaching educational public policy in partnership with the university and Getúlio Vargas State College. The objective of this work is to verify if the methodologies and pedagogical strategies used in the classroom are orienting students in a way that leads them to know their cultural heritage, having as primary source of knowledge the cultural heritage of São Borja. The group of pibidians of the history subproject, during the course of 2017, developed a patrimonial education project with 8th grade students. In the course of the classes the need arose to verify if the students were able to relate the contents taught in the classes, with the existing patrimony in the city, through an open questionnaire. Thus guided by the quali-quanti methodology and the historiographic, hermeneutical and analytical methods we developed the present research. The results obtained with this research indicated that the students were able to assimilate the theory and relate it to practice, that is, to understand what cultural heritage is and to know the heritage that is part of its history. Besides indicating a satisfaction with the program, the methodologies used in the room and the chosen theme for the school year.
\end{abstract}

Keywords: PIBID; Patrimonial Education; Methodologies.

\title{
1. Introdução
}

O Programa Institucional de Bolsa de Iniciação à docência - PIBID é uma política pública educacional com o objetivo de diminuir o distanciamento entre a realidade encontrada na academia e da realidade que se encontra na escola. A Universidade Federal do Pampa UNIPAMPA, é uma universidade multi-campi, em dez cidades da Metade Sul do Rio Grande do Sul, o PIBID se faz presente em oito campis, que por sua vez está em quatorze cursos de licenciatura. Do totalizante de cursos, temos o curso de Licenciatura em Ciências Humanas, um curso interdisciplinar, que habilita o profissional a atuar nas áreas de História, Geografia, Sociologia e Filosofia e está presente no campus de São Borja.

O subprojeto de História tem parceria com 3 escola do município de São Borja-RS, o Instituto Estadual Padre Francisco Garcia, Colégio Estadual Getúlio Vargas e a Escola Municipal de Ensino Fundamental Vicente Goulart, com 30 bolsistas alunos do curso de Licenciatura em Ciências Humanas, 5 professores supervisores da rede pública de educação básica e 2 supervisores de área ligados a UNIPAMPA. Esta pesquisa se debruça sobre o PIBID no Colégio Estadual Getúlio Vargas, nas turmas de $8^{\circ}$ ano do ensino fundamental, no qual a temática escolhida pelos bolsistas e que foi trabalhada durante o ano de 2017 é a educação patrimonial. 
Segundo as autoras (HORTA, GRUNBERG e MONTEIRO, 1999, p. 4) educação patrimonial é "um instrumento de 'alfabetização cultural' que possibilita ao indivíduo fazer a leitura do mundo que o rodeia, levando-o à compreensão do universo sociocultural e da trajetória histórico-temporal em que está inserido". De acordo com as mesmas autoras, esse processo leva ao reforço da identidade dos sujeitos e das comunidades além do reconhecimento da cultura nacional, entendida como múltipla e plural.

Afinal o que é patrimônio cultural? Antes de responder tal pergunta precisamos deixar claro um outro conceito, o de patrimônio. Para Ferreira (apud SIBONY, 1998, p. 80) "patrimônio simboliza uma forma de vida fixada, 'algo que se realizou naquele objeto ou construção'; ou seja, patrimônio é portador de tempo e vivências. "

Pensando no patrimônio como portador de tempo e vivências, o patrimônio cultural seria todas as manifestações e expressões criadas pelo homem e pela sociedade, que vão se acumulando ao longo dos anos, é a expressão de cada geração (GRUNBERG, 2007, p. 4). Ou seja, o patrimônio cultural é o produto de um determinado grupo sociocultural em um determinado tempo histórico, e esse patrimônio carrega consigo expressões, manifestações e vivencias experimentadas por esse grupo. Ainda segundo a autora (GRUNBERG 2007, p. 45), patrimônio cultural também é entendido como:

Todo esse Patrimônio, material, imaterial, consagrado e não consagrado entendendo os primeiros como os reconhecidos pela sociedade e protegidos por legislações (leis e decretos), e os segundos como aqueles que fazem parte do nosso dia a dia, de nossa realidade, revelando os múltiplos aspectos que a cultura viva de uma comunidade pode apresentar - que podemos trabalhar num processo constante de conhecimento e descoberta.

A educação patrimonial trabalhada no subprojeto de história teve como objeto de estudo o patrimônio cultural de São Borja-RS. Uma cidade fronteiriça, a primeira dos 7 povos das missões, com raízes históricas dos nativos índios Guaranis e dos padres Jesuítas, além de ter sido a cidade natal de dois presidentes do Brasil, Getúlio Vargas e João Goulart. Para preservar o patrimônio material herdado dos contextos históricos citados anteriormente, existem 4 museus pela cidade, ideais para o exercício de metodologias da educação patrimonial. As autoras (HORTA, GRUNBERG e MONTEIRO, 1999, p. 7) explicam que "nada substitui o objeto real como fonte de informação sobre a rede de relações sociais e o 
contexto histórico em que foi produzido, utilizado e dotado de significado pela sociedade que o criou. ", também afirma as autoras que, interpretar essas informações amplia a capacidade de compreender a realidade, um objetivo da educação básica.

A educação patrimonial é o tema do projeto para o ano letivo de 2017 , tal projeto tem por objetivo levar crianças e adolescentes a conhecer, valorizar e apropriar-se da sua herança cultural tendo como fonte primaria do conhecimento o patrimônio cultural da cidade de São Borja.

O presente trabalho surgiu a partir da necessidade de verificar se as metodologias e estratégias pedagógicas utilizadas em sala, estavam orientando os alunos de maneira que os levem a conhecer sua herança cultural, além de servir como um instrumento de avaliação do programa e do tema escolhido para o corrente ano.

\section{Metodologia}

A presente pesquisa possui por metodologia utilizada a quali-quanti através dos métodos historiográfico, hermenêutico e analítico. Utilizamos a quali-quanti, pois se torna uma ferramenta melhorada para podermos entender de uma forma mais eficaz o nosso objeto de estudo, através do contexto e da quantificação do mesmo. Os métodos são utilizados de acordo com cada fase da pesquisa, o historiográfico como um resgate do tema e das principais discussões a respeito da problemática, o hermenêutico nos possibilita conhecer e entender o nosso objeto através da interpretação, tanto do contexto quanto o dos números e o método analítico utilizamos quando há a transformação das respostas em números e por sua vez, gráficos e tabelas; e pautados pela técnica de pesquisa questionário podemos executar esta pesquisa.

A técnica de pesquisa utilizada foi o questionário aberto, o mesmo contou com quatro questões e foi aplicado em três turmas do $8^{\circ}$ ano do ensino fundamental, do Colégio Estadual Getúlio Vargas. As duas primeiras questões foram sobre educação patrimonial, e as outras duas a respeito do programa e das aulas. Com a finalidade de avaliar as práticas pedagógicas dos pibidianos e qual o parecer dos alunos sobre o programa institucional.

\section{Resultados e discussões}

O embasamento da pesquisa se resulta em um questionário com quatro perguntas. As duas primeiras relacionadas ao conteúdo do projeto, com o objetivo de avaliar se os principais conceitos da educação patrimonial, presente na cartilha do Iphan e ministrados nas aulas dos 
meses de abril, maio e junho, foram bem compreendidos pelos alunos, pois seria de extrema relevância para as futuras oficinas práticas e aulas de campo, um aprendizado significativo da teoria. Já as últimas perguntas, tiveram o objetivo de avaliar o PIBID e o projeto do ano de 2017. As questões foram as seguintes: a) O que é patrimônio cultural?; b) Quais patrimônios materiais de São Borja - RS você gostaria de visitar?; c) O que você gostaria que mudasse nas aulas do PIBID?; d) O que você tem achado do PIBID?

A primeira pergunta, (a), diz respeito a um importante conceito da educação patrimonial, o de patrimônio cultural. Entendemos a importância de avaliar se tal conceito foi bem compreendido pelos alunos, evitando assim confusões com outras definições. As respostas dos alunos foram quantificadas em: Plenamente satisfatório, aquelas respostas que estavam completas e de acordo com os exemplos e os textos utilizados em sala; Satisfatório, as respostas que estavam incompletas, mas não fugiam muito da definição utilizada; e Insatisfatório, respostas que estavam totalmente em desacordo com o conceito e o autor citado nas aulas. A tabela seguinte tem por finalidade apresentar a avaliação para qualitativa das respostas dos alunos dividido por turmas, e o total por cada categoria.

Tabela 1- Quantitativo referente às respostas da pergunta ${ }^{\circ} 01$

\begin{tabular}{|c|c|c|c|c|c|c|c|c|}
\hline \multicolumn{8}{|c|}{ Pergunta 1) O que é patrimônio cultural? } \\
\hline Turmas & $\begin{array}{c}\text { Plenamente } \\
\text { Satisfatório }\end{array}$ & $\%$ & Satisfatório & $\%$ & Insatisfatório & $\%$ & Não & $\%$ \\
\hline 81 & 8 & 42,1 & 4 & 21 & 6 & 31,5 & 1 & 5,2 \\
\hline 82 & 8 & 34,7 & 11 & 48 & 2 & 8,6 & 2 & 8,6 \\
\hline 83 & 4 & 17,3 & 18 & 78,2 & 0 & 0 & 1 & 4,3 \\
\hline TOTAL & $\mathbf{2 0}$ & $\mathbf{3 0 , 7}$ & $\mathbf{3 3}$ & $\mathbf{5 0 , 7}$ & $\mathbf{8}$ & $\mathbf{1 2 , 3}$ & $\mathbf{4}$ & $\mathbf{6 , 1}$ \\
\hline
\end{tabular}

A partir da análise da tabela, podemos tirar as primeiras conclusões, $80 \%$ dos alunos conseguiram assimilar completamente ou parcialmente o conceito. O quesito satisfatório obteve a maior porcentagem $50,7 \%$, revelando que os alunos sabem o que é patrimônio cultural mas possui algumas dúvidas. $12 \%$ dos alunos não conseguiram compreender o que é patrimônio cultural. O que foi motivo para reflexões, pois a tabela deixou evidente a diferença no aprendizado entre as turmas e a necessidade de se trabalhar metodologias específicas para se atingir um nível razoável do conhecimento, entre eles, sobre as teorias relacionadas a temática, para que as aulas práticas e de campo não se viesse a se tornar uma atividade sem reflexão. 
Dois objetivos pautaram a segunda pergunta, (b). O primeiro, saber se os alunos conheciam os patrimônios materiais da sua cidade, e de acordo com os patrimônios citados por eles, avaliar se os mesmos dominavam o conceito de patrimônio material. Ou seja, se o aluno citava um patrimônio local e o mesmo era um patrimônio material reconhecido pelas instituições de reconhecimento de bens culturais, era um sinal de que o estudante conhecia o conceito de patrimônio material. O segundo objetivo, foi o de realizar uma consulta para saber quais locais eles gostariam de visitar em uma futura aula de campo sobre o patrimônio material local.

A quantificação das respostas foram com base na quantidade de patrimônios materiais citados pelos alunos. Nos casos em que o patrimônio, ou local, não era reconhecido, e não se constituía de fato um patrimônio material da cidade, a resposta foi enquadrada no conceito “confundiu”. Ou seja, o aluno não tinha compreendido a definição de patrimônio material. A seguir a tabela com a porcentagem dos dados quantificados.

Tabela 2 - Quantitativo referente às respostas da pergunta $\mathrm{n}^{\circ} 02$

\begin{tabular}{|c|c|c|c|c|c|c|c|c|}
\hline \multicolumn{7}{|c|}{ Pergunta 2) Quais patrimônios materiais de São Borja - RS você gostaria de visitar? } \\
\hline Turmas & $\begin{array}{c}\text { Nenhum } \\
\text { patrimônio }\end{array}$ & $\%$ & $\begin{array}{c}1-2 \\
\text { Patrimônios }\end{array}$ & $\%$ & $\begin{array}{c}3-5 \\
\text { Patrimônios }\end{array}$ & $\%$ & Confundiu & $\%$ \\
\hline 81 & 1 & 5,2 & 9 & 47,3 & 0 & - & 9 & 47,3 \\
\hline 82 & 4 & 17,3 & 11 & 47,8 & 2 & 8,6 & 6 & 26 \\
\hline 83 & 5 & 21,7 & 14 & 60,1 & 0 & - & 4 & 17,3 \\
\hline TOTAL & $\mathbf{1 0}$ & $\mathbf{1 , 5}$ & $\mathbf{3 4}$ & $\mathbf{5 2 , 3}$ & $\mathbf{2}$ & $\mathbf{3}$ & $\mathbf{1 9}$ & $\mathbf{2 9 , 2}$ \\
\hline
\end{tabular}

A análise da tabela acima se dá a partir de que apenas 3\% dos alunos possuem um conhecimento ampliado dos patrimônios materiais na cidade, e consequentemente, uma maior compreensão da história local. 52\% desses alunos sabem o que é patrimônio material, mas conhecem pouco sobre a história e os patrimônios reconhecidos. $29 \%$ dos alunos não dominam o conceito de patrimônio material e nem conhecem quais bens materiais são reconhecidos pelos órgãos governamentais. E ainda, 1,5\% não citaram nenhum patrimônio material o que acusa esses alunos de não terem compreendido o conceito, ou não ter conseguido relacionar a teoria com a prática, o conceito com os patrimônios materiais que fazem parte da sua cultura.

$\mathrm{Na}$ turma $81 \mathrm{um}$ dado se mostrou interessante, a quantidade de alunos que confundiram patrimônios materiais foi igual para aqueles que citaram de 1 a 2 patrimônios. 
A terceira pergunta, (c), abre o bloco de questões a respeito do programa. Nessas perguntas buscamos conhecer a opinião dos alunos sobre o PIBID, as metodologias e o tema da educação patrimonial. Quantificamos as respostas dos alunos em 3 grandes grupos: Não "mudaria nada das aulas", ou seja, a metodologia e o tema estão agradando; "Mudaria a forma da aula", ou seja, as práticas pedagógicas junto com os materiais utilizados em sala não estão agradando; "Mudaria o tema", ou seja, o tema não é de interesse dos alunos, o que gera um desinteresse pelas aulas. A tabela a seguir deixa bem claro as porcentagens de cada resposta:

Tabela 3 - Quantitativo referente às respostas da pergunta $\mathrm{n}^{\circ} 03$

\begin{tabular}{|c|c|c|c|c|c|c|c|c|}
\hline \multicolumn{8}{|c|}{ Pergunta 3) O que você gostaria que mudasse nas aulas do PIBID? } \\
\hline Turmas & Nada & $\%$ & $\begin{array}{c}\text { Forma da } \\
\text { Aula }\end{array}$ & $\%$ & $\begin{array}{c}\text { Mudaria o } \\
\text { tema }\end{array}$ & $\%$ & $\begin{array}{c}\text { Não } \\
\text { Respondeu }\end{array}$ & $\%$ \\
\hline 81 & 7 & 36,8 & 9 & 47,3 & 1 & 5,2 & 9 & 10,5 \\
\hline 82 & 14 & 60,8 & 8 & 34,7 & 1 & 4,3 & 6 & 0 \\
\hline 83 & 19 & 82,6 & 2 & 8,6 & 2 & 8,6 & 4 & 0 \\
\hline TOTAL & $\mathbf{4 0}$ & $\mathbf{6 1 , 5}$ & $\mathbf{1 9}$ & $\mathbf{2 9 , 2}$ & $\mathbf{4}$ & $\mathbf{6 , 1}$ & $\mathbf{1 9}$ & $\mathbf{3}$ \\
\hline
\end{tabular}

A partir da análise da tabela 03, observamos que apenas $6 \%$ dos alunos são avessos ao tema, em contrapartida $61 \%$ são favoráveis ao tema do projeto e estão gostando da forma que as aulas estão sendo ministradas. Porém, uma reflexão sobre as práticas pedagógicas surgiu ao notar-se que quase $30 \%$ dos alunos tendem a querer uma mudança na "forma da aula" onde a mesma fosse diferente. Entretanto chegamos a seguinte conclusão; o tema e as aulas estavam sendo atrativas para a maioria dos discentes. Mesmo com algumas dificuldades no processo de ensino/aprendizagem os educandos se mostraram interessados na temática que os estimulava a querer conhecer mais sobre a história local.

A mudança na forma das aulas veio a partir do momento que conseguimos superar a teoria, delimitar alguns conceitos e suprimir as dúvidas que encontramos no caminho. Após concluir esses objetivos, as aulas seguintes, depois do recesso, iniciadas no mês de agosto, acompanhavam uma revisão teórica e uma prática acompanhada de reflexão, como exemplo tivemos: visitas a museus da cidade, oficina de saber fazer cerâmica guarani e a construção de uma maquete da redução de são Francisco de Borja. Essas oficinas só foram possíveis de serem pensadas a partir das reflexões proporcionado pelo questionário. 


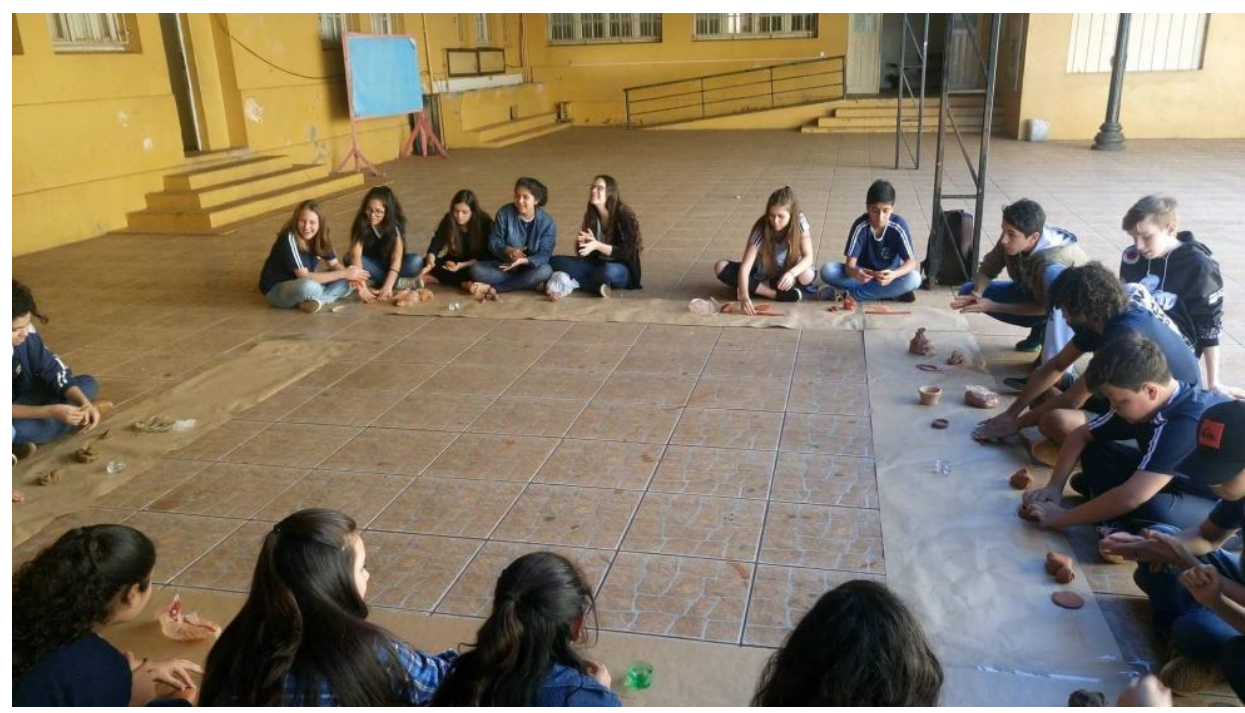

Fotografia 1 - Oficina de cerâmica guarani

A oficina de saber fazer cêramica guarani foi uma das aulas práticas do projeto. $\mathrm{O}$ saber fazer cêramica guarani se constitui como um patrimônio imaterial da região das missões na qual São Borja está inserida. Esse modo próprio dos Guaranis de fazer cêramica vem sendo esquecido a cada nova geração, assim como o oficio de cerâmista. Apresentar aos alunos esse patrimônio imaterial é uma forma de se preservar a cultura e mantendo-a viva para as próximas gerações. Esse é o objetivo do projeto do pibid na escola Getulio Vargas e também da educação patrimonial, levar o aluno a conhecer, valorizar e se apropriar da sua históra e sua cultura.

A quarta e última pergunta, (d), se constitui uma avaliação direta do programa institucional, buscando aferir o nível de satisfação dos alunos com a política educacional. Classificamos as respostas em: Péssimo, o aluno não está gostando nenhum pouco do programa; Bom, o aluno está gostando do programa, mas tem algumas críticas a ser colocada; e, excelente, no qual o aluno está muito satisfeito com o programa.

Tabela 4 - Quantitativo referente às respostas da pergunta $\mathrm{n}^{\circ} 04$

\begin{tabular}{|c|c|c|c|c|c|c|c|c|}
\hline \multicolumn{8}{|c|}{ Pergunta 4) O que você tem achado do PIBID? } \\
\hline Turmas & Péssimo & $\%$ & Bom & $\%$ & Excelente & $\%$ & Não & $\%$ \\
& & & & & & & & Respondeu \\
\hline 81 & 0 & - & 10 & 53 & 8 & 42 & 1 & 5,2 \\
\hline
\end{tabular}


RELACult - Revista Latino-Americana de Estudos em Cultura e Sociedade

\begin{tabular}{|c|c|c|c|c|c|c|c|c|}
\hline 82 & 1 & 4,3 & 8 & 35 & 12 & 52,1 & 2 & 8,6 \\
\hline 83 & 1 & 4,3 & 7 & 30 & 13 & 56,5 & 2 & 8,6 \\
\hline TOTAL & $\mathbf{2}$ & $\mathbf{3}$ & $\mathbf{2 5}$ & $\mathbf{3 8 , 4}$ & $\mathbf{3 3}$ & $\mathbf{5 1}$ & $\mathbf{5}$ & $\mathbf{7 , 6}$ \\
\hline
\end{tabular}

Analisando a tabela acima, podemos perceber que apenas 3\% dos alunos reprovam a política educacional, enquanto $51 \%$ deles estão satisfeitos com o programa e até apontam em suas respostas que o PIBID proporciona um conhecimento diferente das matérias curriculares convencionais. E, 38\% dos alunos aprovam o programa mas apontam algumas críticas, como a necessidade de mais períodos na semana.

Esses dados reforçam como o pibid vem ganhando o respeito, aceitação e espaço dentro da comunidade escolar de São Borja. E, além de aproximar licenciados a realidade escolar, também tem aproximado a comunidade escolar a universidade. A aprovação de mais de $89 \%$ dos alunos diz muito sobre a relação entre pibidianos, universitários, e os alunos da educação básica.

\section{Conclusões}

Essa pesquisa obteve o objetivo de estudar as metodologias aplicadas em sala de aula, onde as mesmas estão ou não surtindo efeitos e qual é o feedback acerca das aulas, ou seja, uma avaliação dos resultados alcançados, tanto das práticas pedagógicas, como do PIBID no Colégio Getúlio Vargas. Tal feedback proporcionou ao grupo um material para analisar como o conteúdo ministrado conseguiu, ou não, acessa o aluno. E a forma como o aluno estava apreendendo. O que pretendíamos era checar se a teoria foi bem assimilada, para que posteriormente a prática não se tornasse mera técnica sem reflexão, orientando assim o aluno a apropriar-se de sua herança cultural, capacitando-o para um uso consciente destes bens.

A reflexão acerca dessa pesquisa deu origem a reuniões para repensar coletivamente as práticas pedagógicas do pibidianos, e o cronograma do segundo semestre do projeto para o ano letivo de 2017, o qual foi colocado em prática no mês de Agosto. Tomamos como base as considerações e sugestões dos alunos, que pediram mais aulas práticas, e a oficina de cerâmica, citada anteriormente, foi fruto dessas reuniões. Assim buscamos tornar o processo de ensino/aprendizagem mais dinâmico, mais divertido, porque concordamos que a atividade do conhecimento tem que ser prazerosa para atrair o interesse do aluno. 
Assim compreendemos e salientamos a importância das avaliações pedagógicas e metodológicas no processo de ensino/aprendizagem, e não apenas a avaliação do aluno com provas e testes. Preocupar-se com as metodologias é estar preocupado também em conhecer melhor o perfil do aluno e das turmas para saber quais recursos pedagógicos utilizar.

Obtivemos com o questionário fontes para argumentar a favor da continuidade do programa dentro da Universidade Federal do Pampa - UNIPAMPA. Esse tipo de trabalho ajuda a reforçar como essa política educacional vem cumprindo bem seus principais objetivos, preparando o futuro formando para os estágios, e futuramente o seu ambiente de trabalho, visto que a escola é um ambiente complexo que necessita de experiencia e pratica para se conseguir exercer bem a profissão.

\section{Referências}

BAQUERO, Marcello. Pesquisa quantitativa nas Ciências Sociais. Porto Alegre: UFRGS, 2009.

FERREIRA, Maria Letícia Mazzucchi. Patrimônio: discutindo alguns conceitos. Diálogos Revista do Departamento de História e do Programa de Pós-graduação em História, Maringá, v. 10, n. 3, p.79-88, 2006.

GRUNBERG, Evelina. Manual de atividades práticas de Educação Patrimonial. Brasília: IPAHN, 2007.

HORTA, Maria de Lourdes Parreiras; GRUNBERG, Evelina; MONTEIRO, Adriane Queiroz. Guia básico de educação patrimonial. Brasília: Iphan, 1999.

LAKATOS, Eva Maria. Fundamentos de metodologia científica. São Paulo: Ed. Atlas, 2010.

MINAYO, Maria Cecilia de Souza de (org) Pesquisa Social: Teoria Método e Criatividade. Petrópolis, RJ: Vozes 2002.

RANGEL, Mary. Métodos de ensino para a aprendizagem e a dinamização das aulas 6 ed. Campinas: Papirus, 2010. 